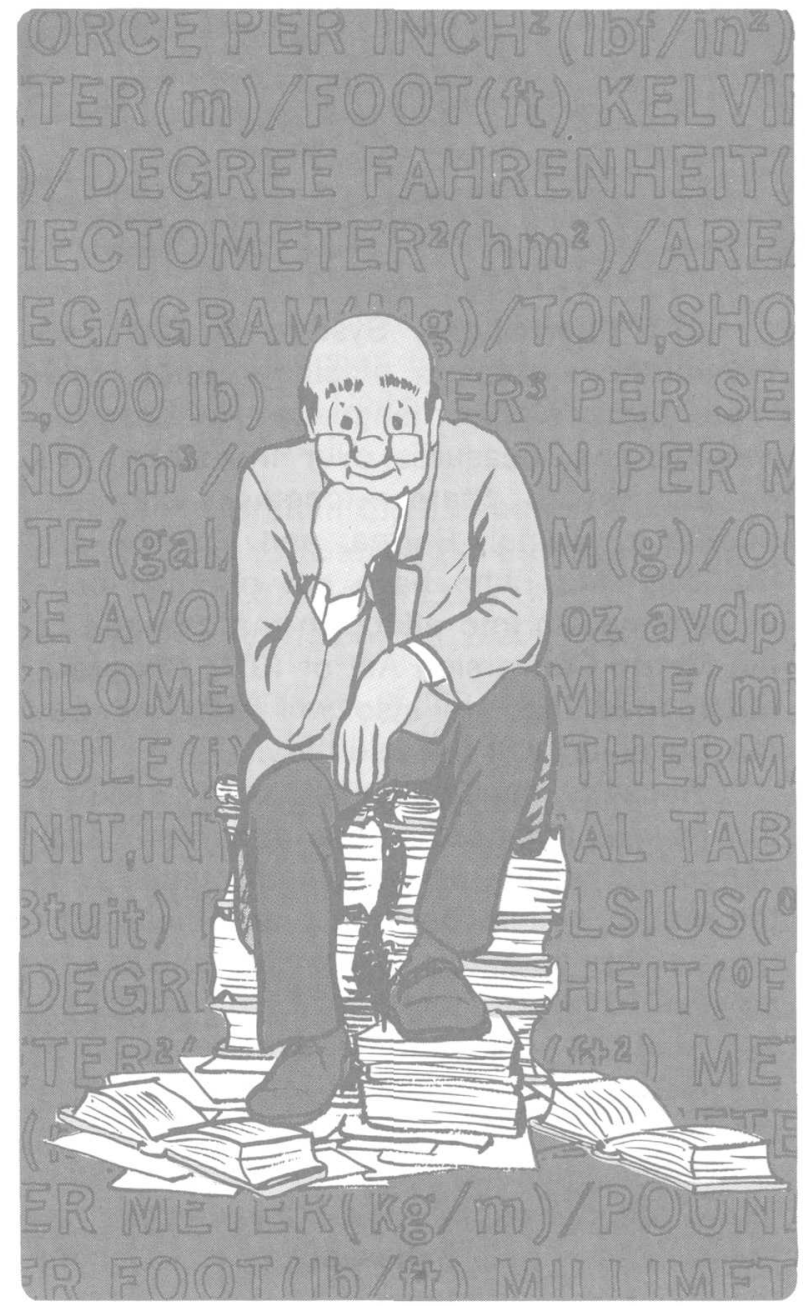




\section{Think Metric}

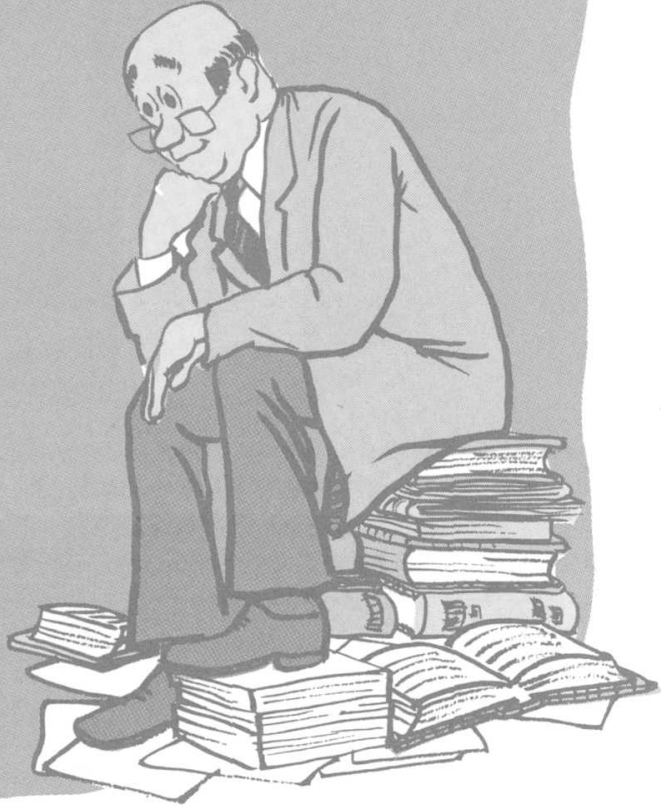

The International System of Units, as the metric system is officially called, provides for a single "language" to describe weights and measures over the world. We in the United States-together with the people of Brunei, Burma, and Yemen-are the only ones who have not put this convenient system into effect. In the passage of the Metric Conversion Act of 1975, Congress determined that we also will adopt it, but the transition will be voluntary.

Recently, the Geological Survey decided that its scientific publications, and most maps, henceforth would use only metric units. With the metric system becoming an official language, the time has come for USGS employees to start thinking in metric terms.

Many of us are turned away from use of the metric system because of the fear that we will have to learn a lot of complicated conversion factors, each involving a long string of decimals. To start thinking metric, however, it is only necessary to learn about ten rough approximations.

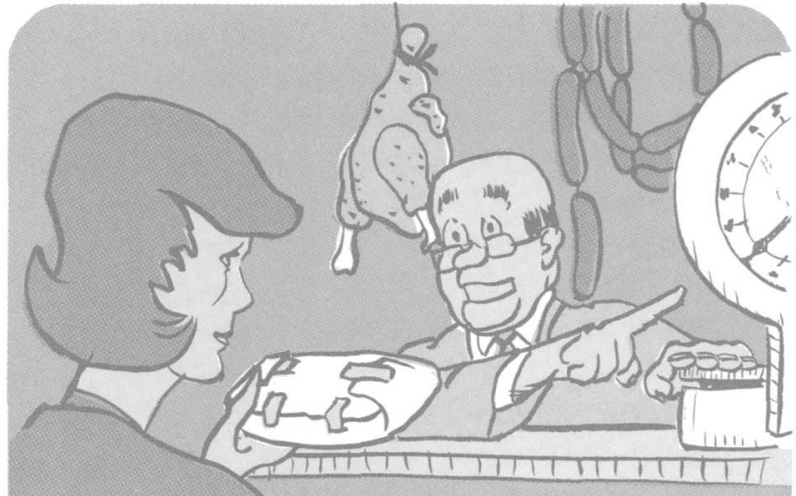

If we need exact measurements, we can make them with instruments calibrated in metric units, just as we do in making measurements in U.S. customary units, or we can refer to conversion tables and devices that are widely available. For many purposes, though, approximations are enough. So why not forget the exact decimal equivalents and just think of a kilogram as a little more than two pounds, a liter as a little more than a quart, a meter as a little more than a yard, and a kilometer as just a bit more than half a mile?

Approximations won't always work. Applying the last approximation to figuring out the 55 miles per hour ( $\mathrm{mph}$ ) speed limit in metric terms would give us about 110 kilometers per hour $(\mathrm{km} / \mathrm{h})$, too much on the high side of the $88 \mathrm{~km} / \mathrm{h}$ exact equivalent to keep us out of legal trouble. For such purposes it's better to use a little more precise equivalent-1 kilometer $=0.6$ miles-but one still easy for mental arithmetic.

Illustrated are some of the common metric units and their customary system equivalents, followed by the approximations that we need to have in mind while we are in the process of beginning to think metric in everyday life. We say "in the process" because it won't take long to achieve enough basic familiarity with metric units to stop us from worrying about conversion factors altogether. 

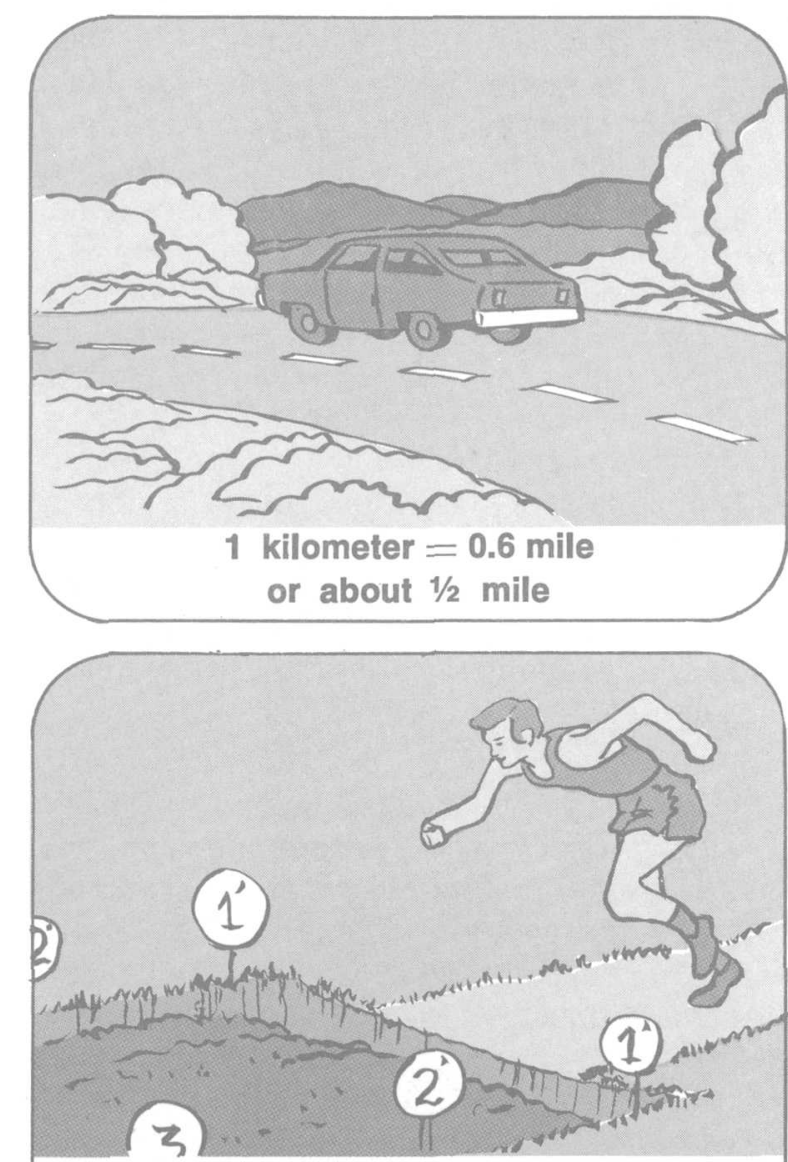

1 meter $=1.1$ yards or about 1 yard or 3 feet

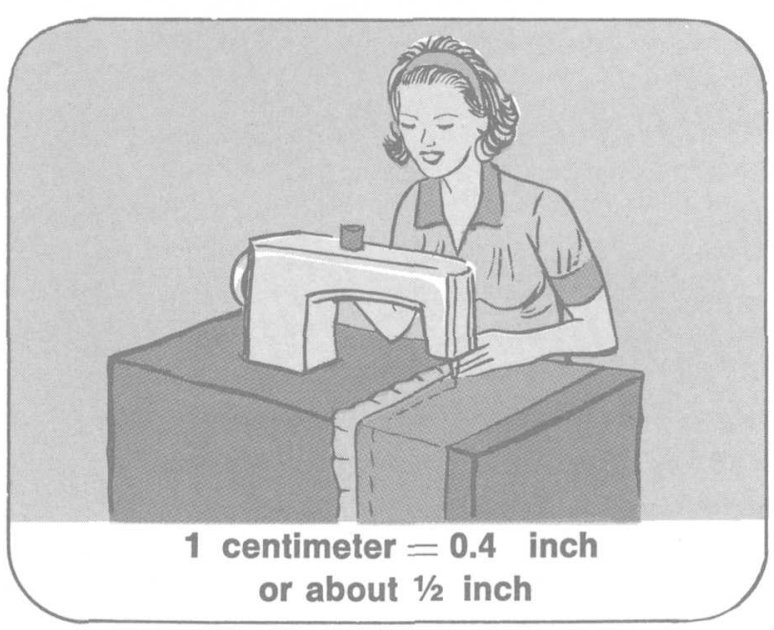

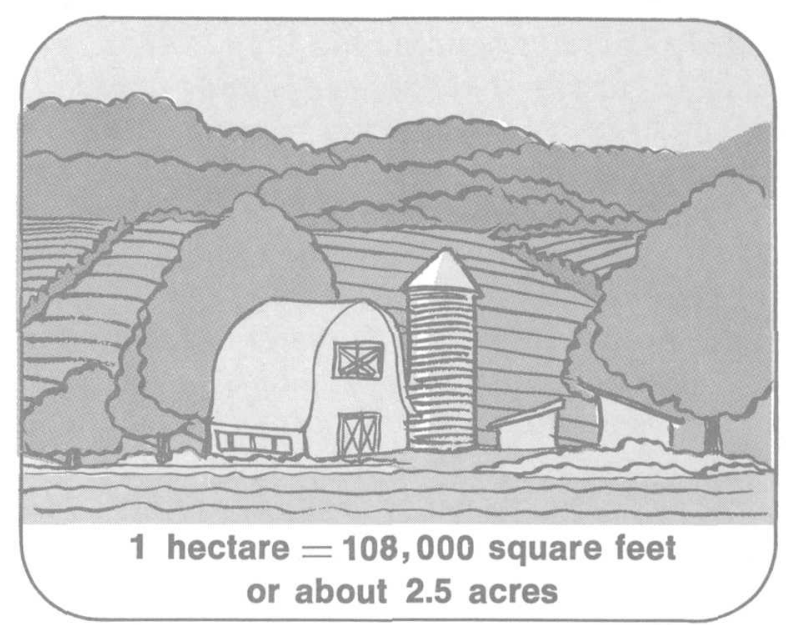
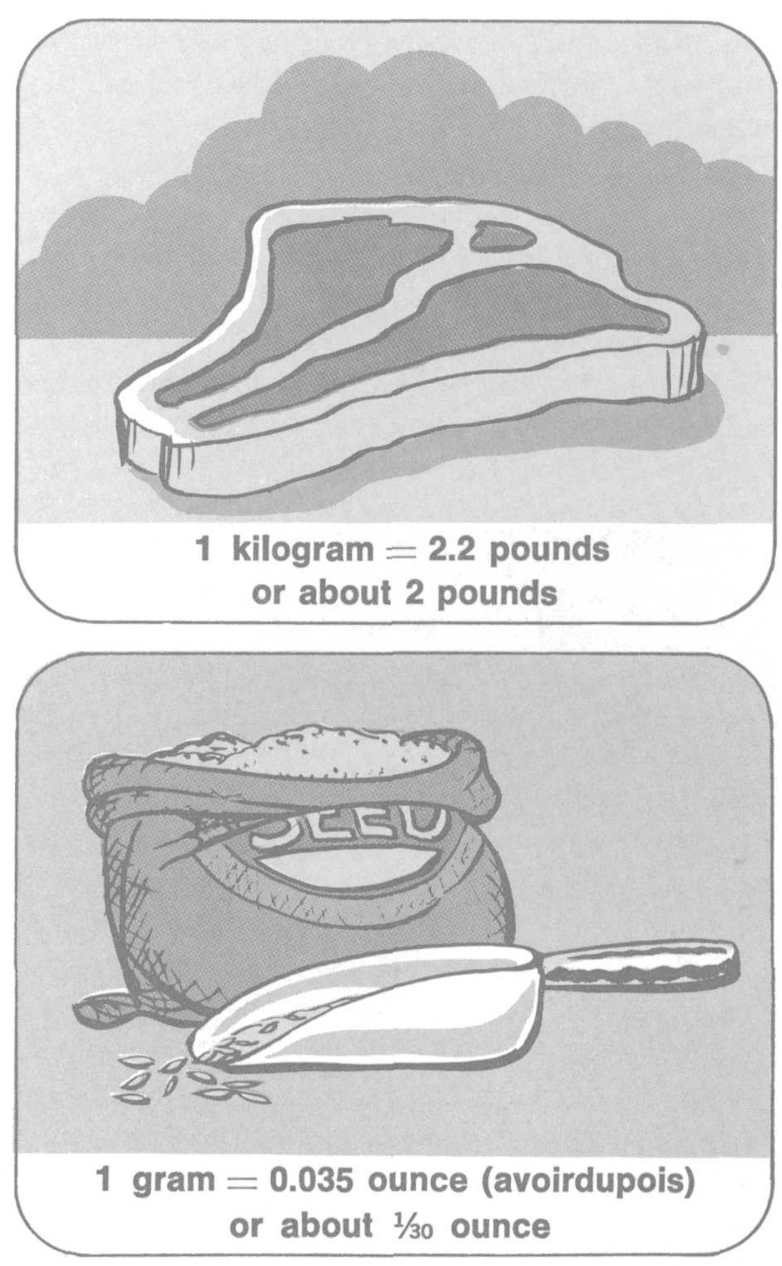
or about $1 / 30$ ounce
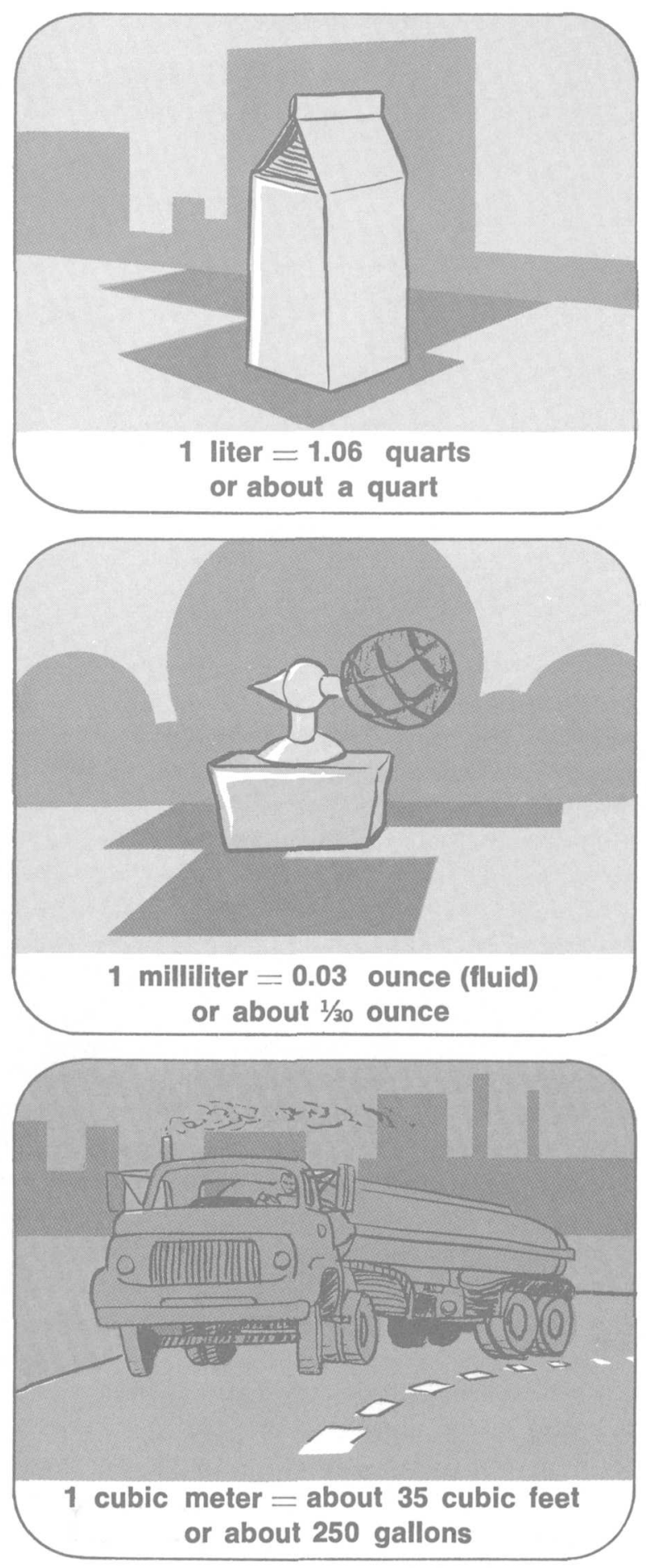


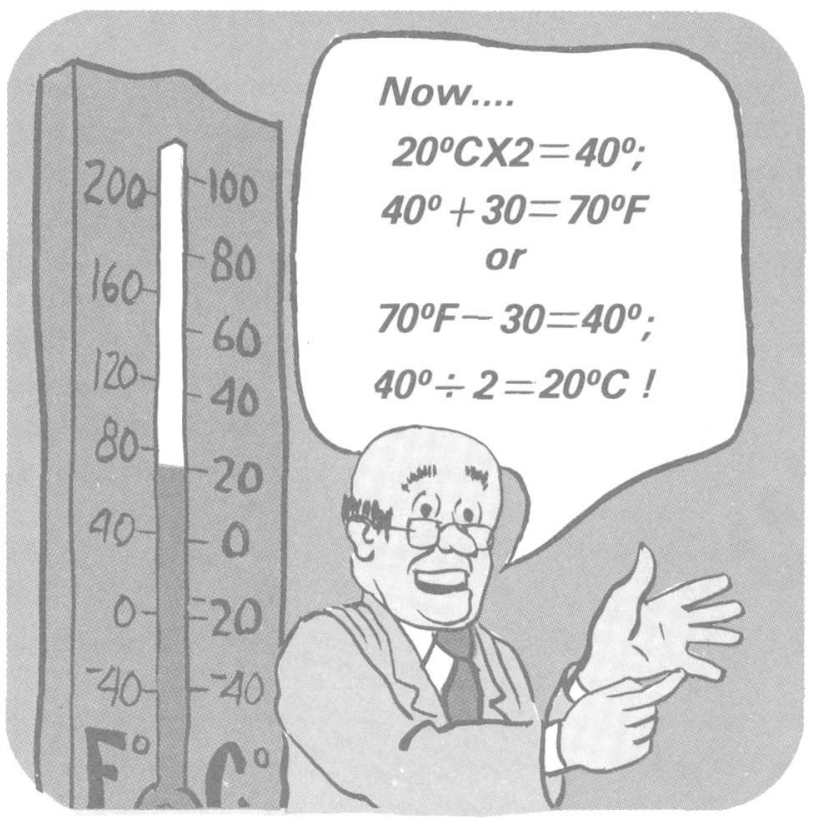

For approximate temperature conversions, all we really need to remember is that the freezing and boiling points of water on the Celsius (C) scale are $0^{\circ}$ and $100^{\circ}$, respectively, instead of $32^{\circ}$ and $212^{\circ}$ as on the Fahrenheit (F) scale and that "room temperature" is $20^{\circ} \mathrm{C}$ instead of $68^{\circ} \mathrm{F}$. If we do need to convert from Celsius to Fahrenheit, in the temperature range of most weather reports, it's close enough to multiply degrees $C$ by 2 and add 30 to determine degrees Fahrenheit; or to convert Fahrenheit to Celsius subtract 30 from degrees $F$ and divide by 2 .

Some of these simple approximations are already being used by manufacturers of kitchen measures which show, for example, a cup ( $1 / 2$ pint) to be about the same as 250 $\mathrm{mL}$ (milliliters) or about $1 / 4$ liter. This is the principle we're talking about-for many recipes it won't matter much whether a bit more or less milk or flour is added. Keep in mind that many recipes use such international approximations as a "pinch," "dash," and "walnut-size." If a bit more or less does matter use an exact metric measure or conversion factor. Start reading the labels on packages, cans, and bottles. Most manufacturers are now giving their contents in exact customary and metric units, which will help us test and refine our approximations.

The benefits of "thinking metric" lie in the basic advantage of the system-its units increase or decrease by units of ten and the same prefixes, with rare exceptions, apply whether we're dealing with length, weight, or area. A kilometer is 1,000 meters; a kilogram is 1,000 grams; a square kilometer is 1,000 meters squared. One of the rare exceptions is the term liter-a volume measure 1.06 times a quart, to which only the prefix milli (one thousandth) may apply. Remember that when we were learning the multiplication tables, we were home free when we got to the tens. And, for purposes of the approximations mentioned above, recall that the fives weren't too bad either.

In everyday life, you won't need to know more prefixes than kilo $(1,000$ times, such as 1,000 grams), centi (one 100th, such as 100th of a gram) or milli (one 1,000th, such as a 1,000 th of a meter).

One other benefit of the metric system is that most basic units are easily relatable to one another. For example, a cubic centi-

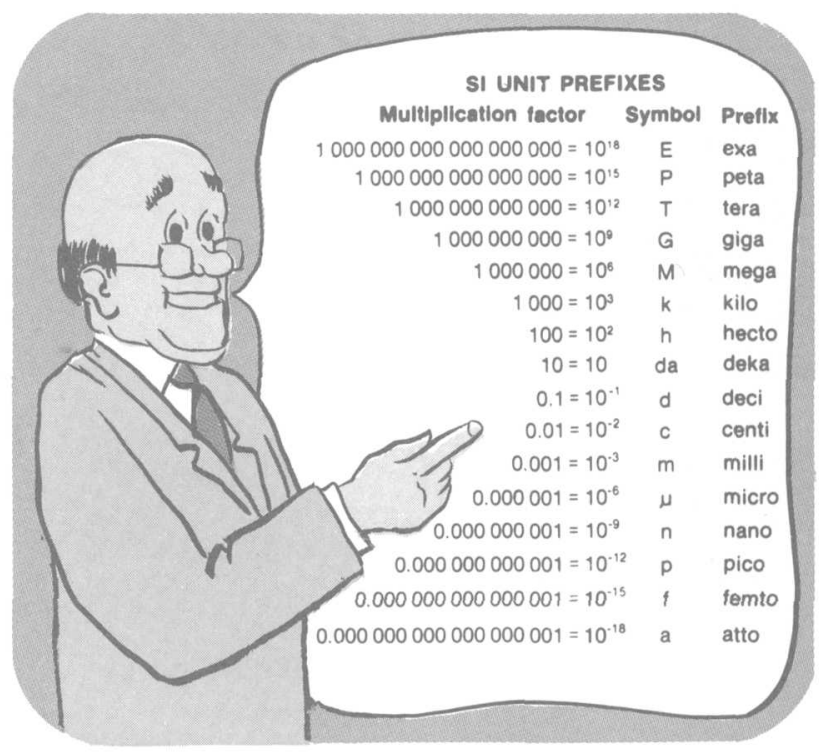

meter $\left(\mathrm{cm}^{3}\right)$ of water weighs 1 gram, so 1,000 $\mathrm{cm}^{3}$ weighs 1,000 grams, and a cubic meter of water $(100 \times 100 \times 100 \mathrm{~cm}=1,000,000$ $\mathrm{cm}^{3}$ ) in the metric system weighs $1,000,000$ grams or 1,000 kilograms. Now try to make the same jump from a volume of water to a weight of water in the U.S. customary units. Sure, you might remember the jingle, "a pint's a pound the world around," but how much does a gallon of water or a barrel of water weigh? Anybody who can remember all the necessary conversion units of the customary system ( 8 pints to a gallon and 31.5 gallons to a barrel, except oil, which is 42 gallons to a barrel) will have no trouble with the metric units. And the rest of us, who never could remember all the customary units, will probably find it a joy to be thinking metric.

For more precise information on the metric system and its customary equivalents, write for "Conversion Factors: SI Metric and U.S. Customary Units." Single copies are free on request to

\section{Branch of Distribution U.S. Geological Survey 1200 South Eads St. Arlington, VA 22202}

Bulk quantities of the above leaflet may be purchased from

Superintendent of Documents U.S. Government Printing Office Washington, DC 20402

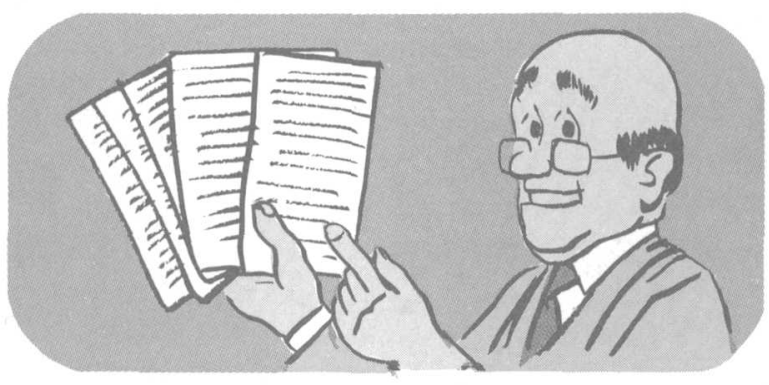

For sale by the Superintendent of Documents, U.S. Government Printing Office ashington, D.C. 20402 
As the Nation's principal conservation agency, the Department of the Interior has responsibility for most of our nationally owned public lands and natural resources. This includes fostering the wisest use of our land and water resources, protecting our fish and wildlife, preserving the environmental and cul. tural values of our national parks and historical places, and providing for the enjoyment of life through outdoor recreation. The Department assesses our energy and mineral resources and works to assure that their development is in the best interests of all our people. The Department also has a major responsibility for American Indian reservation communities and for people who live in Island Territories under U.S. administration.
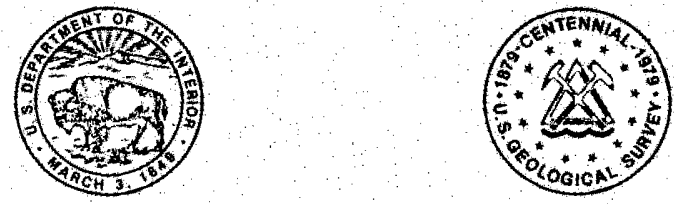